\title{
ENGINEERING TESTING PROCESS \\ MANAGEMENT SYSTEM BASED ON .NET FRAMEWORK
}

\author{
Liang Jin, Gandi Xie, CaiXing Lin
}

College of Mechanicals Engineering and Automation, Shanghai University, Shanghai 200072, China.Email:jackyking2004@163.com

\begin{abstract}
This paper raises the idea that the traditional way to manage engineering testing documents by hands is not competent for Business Process Reengineering after the author has analyzed the status quo of the engineering testing process management in the auto production industries. The author raises Engineering Testing Process Management (ETPM) system software based on ASP.NET technology to solve the practical problems. Additionally, the architecture of the software and the realization of the system are discussed subsequently. The basic model of the ETPM system software and the prime modules which have been developed are introduced.
\end{abstract}

Key words: $\quad$ Engineering Test Process Management, ASP.NET, .NET architecture

\section{INTRODUCTION}

With the development of economy, enterprises faced with greater competition than ever. That demands enterprise to shorten the production cycle. It is proved in practice that Business Process Reengineering (BPR) is the most useful way to enhance the ability of the long-term competition for enterprise strategically.

The new product development in motor manufacturing is composed of design testing and trial-manufacture. There are so many processes in every aspect of them that caused the great complication of the engineering testing

Please use the following format when citing this chapter:

Jin, Liang, Xie, Gandi, Lin, CaiXing, 2006, in International Federation for Information Processing (IFIP), Volume 207, Knowledge Enterprise: Intelligent Strategies In Product Design, Manufacturing, and Management, eds. K. Wang, Kovacs G., Wozny M., Fang M., (Boston: Springer), pp. 978-983. 
process management. So how to improve the engineering testing process management in BPR is becoming one of the crucial factors for the largescale manufacturing enterprise to enhance its ability of competition.

The author raised the ETPM system to solve these problems. The prime modules have been developed successfully, and the software is begun to be applied in practical use.

\section{ANALYSIS OF THE STATUS QUO OF EPTM}

Engineering testing is indispensability in product developing. However, there are many processes and departments involved in this course. The testing documents have to be signed and be delivered by hand under the traditional way. That naturally prolonged the cycle of file delivery.

Obviously, the biggest problem is that all the documents (include test proxy, test program, test project, work order, test monitor data file, etc.) of processes are all finished by hands. That truly causes the low efficiency. Furthermore, some issues which have to be solved in engineering can hardly be realized such as version management, track of process design and so on under the traditional way. Accordingly, that absolutely becomes the bottleneck of the value chain in lean production.

On the other hand, if Chinese economy needs greater development, enterprises must think much of product innovation. Engineering testing is the important course and means in product innovation.

In a word, the effective management in engineering testing will vigorously ameliorate and optimize productivity.

\section{THE MODEL OF ETPM SYSTEM}

According to practical demands, the ETPM system is a full set of computer aided engineering testing process management system.

The design aims of the ETPM system are as follow, (1) It can collect the affairs which are fussy and hard to quantized to one uniform platform for users to deal with. (2) It can supervise the engineering testing documents (especially test proxy, test program, test project, work order, test monitor data file, etc.)systematically and gather those data to form a knowledge base which can supply historical data and data support for new product development in the future. (3) Different authorized user of engineering testing department can finish their respective work in this platform in cooperative way. (4) Authorized user can share the resources on the net 
according to the different purview. Figure 1 shows the systemic management model.

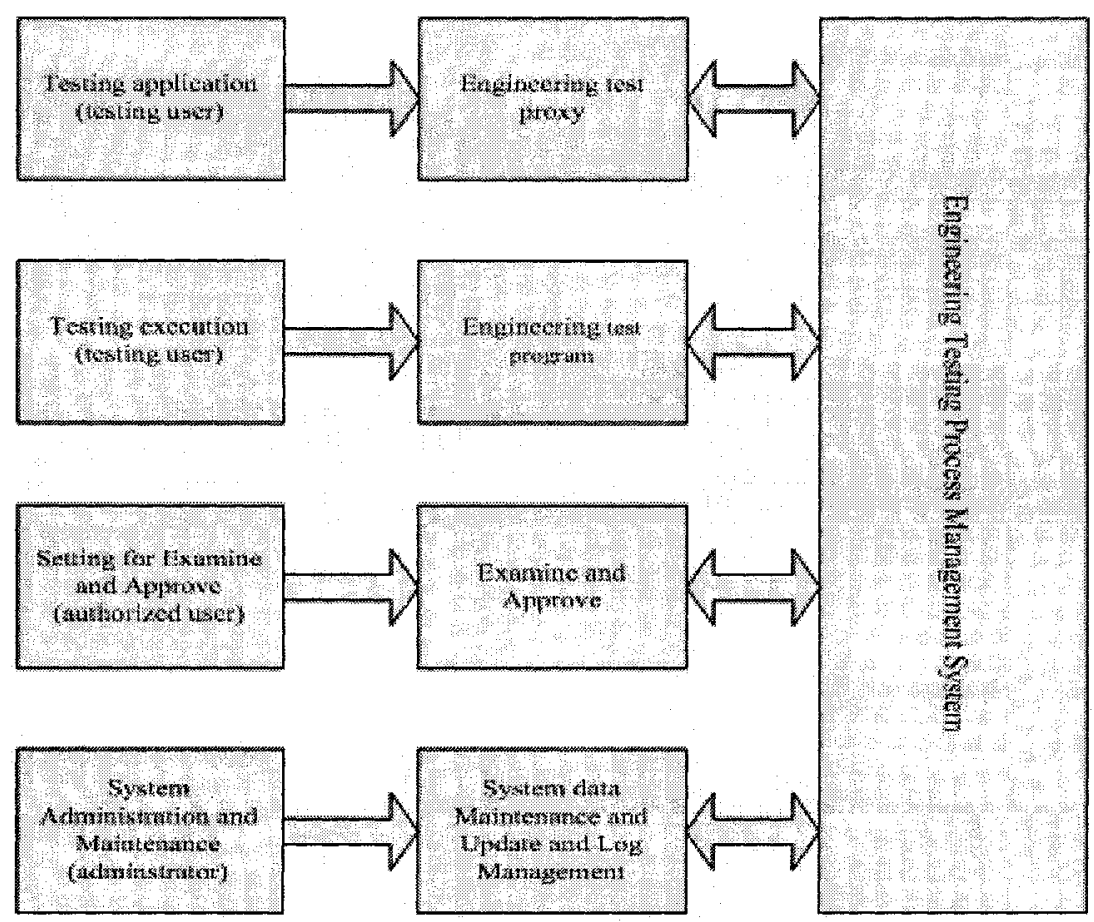

Figure 1: the Systemic Management Model

\section{FUNCTIONAL DESIGN OF ETPM SYSTEM}

The ETPM system is composed of 5 modules. They are test document management module, work project management module, system management module, security management module and examine and approve management module. (See figure 2)

\subsection{Test document management module}

Test document management module is used to realize the foundation and management of the documents, such as test proxy, test program, test project, work order, test monitor data file and so on. 


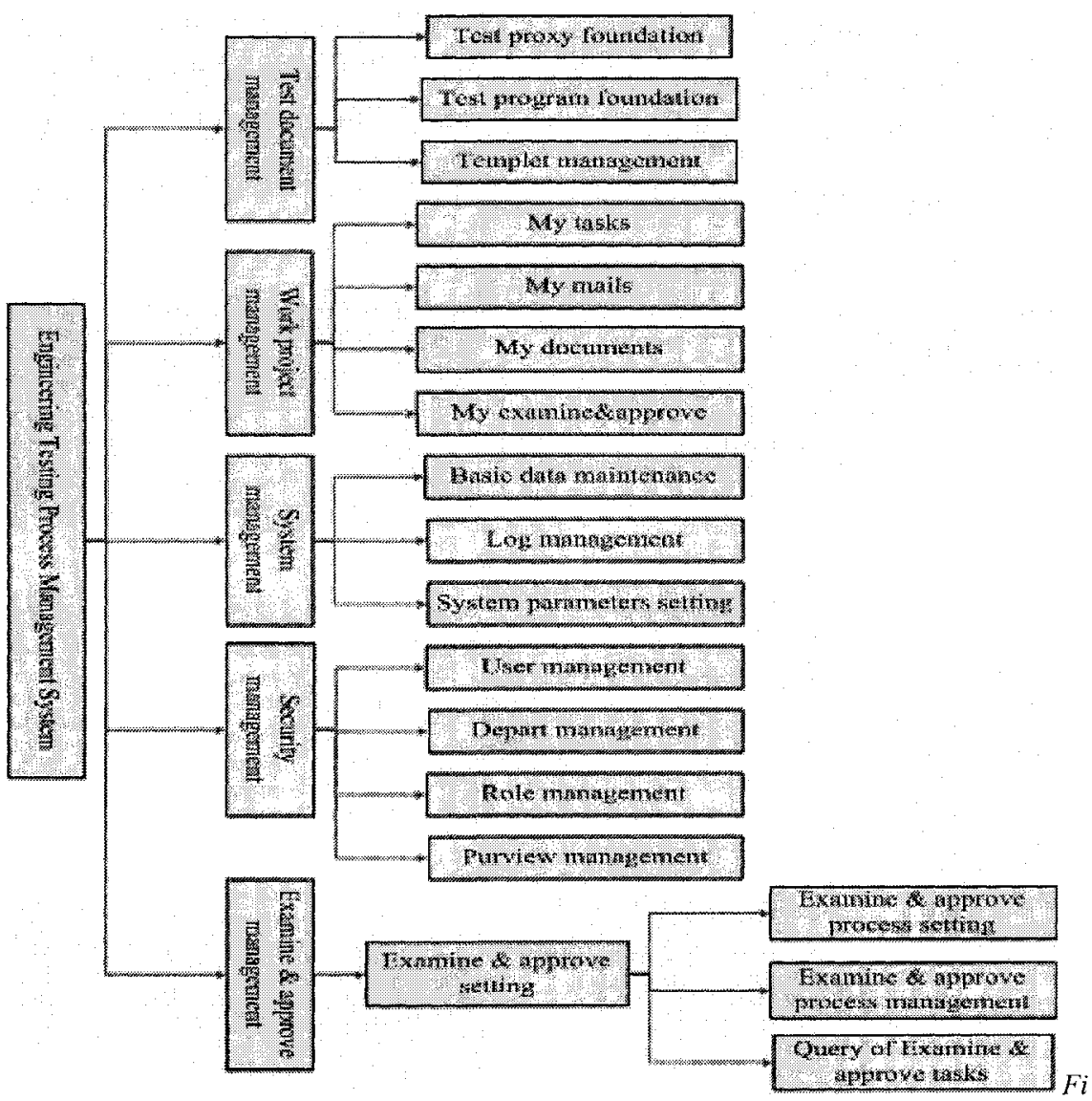

gure 2: the Composition of the ETPM system

Test users who apply for the testing task are able to create new test proxy and test program by this module. User can pick contents from a knowledge base to create documents easily. In addition, user can use the templates stored in the system to create documents since some documents will be used frequently. And all the documents can be appended accessories to make the information of the document intact during the documents foundation.

\subsection{Work project management module}

Work project management module helps user to manage and arrange individual work scheme.

Authorized user can query their task and scheme or execute daily job. And it can help user to finish the tasks in time, such as test application, send 
and receive mails, examine and approve etc.

On the other hand, authorized user can arrange personal task according to own schedule. At the same time, the leaders can master the employee's schedule. The management can be bidirectional. The module also provide special task reminder assistant as an auxiliary function for user. So the online work management is realized. All the users can query the interior sharing resource and browse the real-time news.

\subsection{System management module}

System management module helps system administrator to maintain and update the data of the ETPM system.

The administrator can use the relevant functions which are provided by the ETPM system to fulfill the following tasks. First, the administrator can append, modify, delete and backup both the data of the document knowledge base and the basic information. Second, the administrator can manage the enterprise news and the messages. Third, the administrator can manage the logs which memorize all users' operation records. Fourth, the administrator can fulfill the task of setting system parameters.

\subsection{Security management module}

Security management module also helps system administrator to supervise user, department and role.

This module has the fundamental function of registration and modification for user, department and role. The administrator can use the retrieve tool which is provided by the module to search the basic information of the specified user, role or department quickly, and then the administrator can finish the update operations such as modify and delete. In addition, the system administrator can operator the purview management of user, department and role.

\subsection{Examine and approve management module}

Examine and approve management module provides users the function of foundation of examine and approve task toward the documents applied for authorized user.

After a testing user has submitted the test application documents, the specified user who has the purview to set the examine-and-approve task to create a new examine-and-approve task by this module. The user can arrange different group of people to finish the work of examine and approve according to practical demand. The examine-and-approve types can be 
parallel or serial. The examine-and-approve task really begins after it is completely created. At the same time, a new work task has been produced in the work schedule of the each person of the examine-and-approve group.

\section{TECHNOLOGY REALIZATION OF ETPM}

The ETPM system is based on distributed architecture. The user in the interior LAN can store, dispose, query and supervisor the engineering test documents. The software adopts the $\mathrm{B} / \mathrm{S}$ structure. It is developed by Microsoft ASP.NET technology. All the maintenance and update will be just fulfilled on the server. That makes the cost minimization. The presentation layer is the web platform, the operation toward database and workflow controls are in the middle layer. The relational database, MS SQL Server2000, which lies in the data link layer supplies fundamental database platform.

\section{CONCLUSION}

The ETPM system which this paper discussed is more than software; it is a kind of resolve scheme. It totally meets the demand of the engineering testing process management in the auto production industries. Tough the ETPM system still need to be improved in some aspects, such as the foundation and the management of work process for complex system etc. The ETPM system has realized the foundation, submission, examine and approve, query, monitor etc on the net by the means of advanced platform technology and design structure. It not only supplies a convenient friendly interactive environment for users, but also supports the requirements of distributed application in engineering effectively.

\section{REFERENCE}

1. WANG Zhaixiao LV Lintao YAN Wenyao, Online Endorsement System Based on ASP.NET and Workflow Model, Computer Engineering, vol.30, No.17, 2004, p83-85.

2. Liu Haichuan Chen Peijiu, Design and Implementation of Workflow Management System Based on XML and ASP.NET, Computer Engineering and Application, 2004.15, p214-217.

3. Tu Yan, On Workflow Integration And Engineering Management Information Systems, Journal of Beijing Electronic Science and Technology Institute, vol.12, No.4, 2004, p64-68. 